\title{
Diabetes remission twelve years after laparoscopic adjustable gastric banding
}

Chloe Cheng, John M. Wentworth, Cheryl Laurie, Stewart Skinner, Paul R. Burton, Wendy A. Brown, Paul E. O’Brien

\section{Background}

In the clinical setting, more than half of all patients with Type 2 diabetes mellitus are obese. In this subcategory of patients, surgical options are increasingly being utilised to treat their myriad of metabolic comorbidities. Diabetes remission post-metabolic surgery stems from alterations in foregut hormonal mechanisms, as well as reduction in weight. Of the three most commonly performed metabolic surgical procedures (Roux-en-Y gastric bypass, sleeve gastrectomy and LAGB), the LAGB has the advantage of being the least invasive, reversible and has a low postoperative mortality rate. Although the rates of complications and re-operation in the long-term can be significant, LAGB remains as a therapeutic option for treatment of diabetes in obese patients, especially after careful patient evaluation.

\section{Aim}

The goals of this study were to determine baseline and post-LAGB characteristics associated with type 2 diabetes remission (cessation of hypoglycaemic medication and HbAlc of less than $6.5 \%$ ) 12 years after receiving metabolic surgery.

\section{Methods}

An observational cohort of I/3 diabetic participants (mean BMI, 42.9) who underwent LAGB between January 20th, 2003 and February 2Ist, 2005, at the Avenue Hospital (Melbourne, Australia) were contacted (in-person at outpatient clinic, by telephone or email) for evaluation. Of the $1 / 3$ participants enrolled, 60 (53.1\%) presented for review 12 years post-LAGB. Data collection was performed retrospectively to assess diabetes status at baseline and at 12 years. Fisher's exact test and unpaired $t$ tests were used to analyse the data.

\begin{tabular}{|c|c|c|c|c|c|}
\hline & $\begin{array}{l}\text { Did not go into } \\
\text { remission } \\
(n=52)\end{array}$ & $\begin{array}{l}\text { Standard } \\
\text { Deviation }\end{array}$ & $\begin{array}{l}\text { Diabetes } \\
\text { remission }(n=8)\end{array}$ & $\begin{array}{l}\text { Standard } \\
\text { Deviation }\end{array}$ & p value \\
\hline \multicolumn{6}{|l|}{ Baseline characteristics } \\
\hline Female (\%) & $50.00 \%$ & & $50.00 \%$ & & \\
\hline Male (\%) & $50.00 \%$ & & $50.00 \%$ & & \\
\hline Mean age (years) & 50.10 & 7.05 & 44.48 & 6.16 & 0.0375 \\
\hline Mean weight (kilograms) & 121.33 & 25.16 & 125.80 & 31.16 & 0.5811 \\
\hline 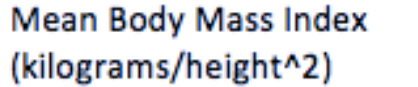 & 42.24 & 7.65 & 43.44 & 10.04 & 0.6935 \\
\hline Diabetes duration (years) & 5.32 & 5.87 & 1.36 & 2.16 & 0.0656 \\
\hline Current smoker (\%) & 13.46 & & 0.00 & & 0.5782 \\
\hline Ex-smoker (\%) & 42.31 & & 37.50 & & 1 \\
\hline Never smoked (\%) & 44.23 & & 62.50 & & 0.4543 \\
\hline Insulin use (\%) & 21.15 & & 0.00 & & 0.3301 \\
\hline Metformin use (\%) & 69.23 & & 75.00 & & 1 \\
\hline Sulphonylurea use (\%) & 40.38 & & 25.00 & & 0.6983 \\
\hline $\begin{array}{l}\text { Mean fasting glucose } \\
\text { (mmol/L) }\end{array}$ & 9.56 & 3.19 & 7.19 & 2.43 & 0.0493 \\
\hline HbA1c (\%) & 8.27 & 1.35 & 6.98 & 1.68 & 0.0179 \\
\hline
\end{tabular}

\section{Results}

The diabetes remission rate 12 years post-LAGB was $13.3 \%(n=8)$. The male to female ratio was I:I. Significant baseline characteristics associated with type 2 diabetes remission was a younger age at time of LAGB insertion $(p=0.0375)$, lower baseline fasting blood glucose $(p=0.0493)$ and a lower baseline HbAlc $(p=0.0179)$.

\begin{tabular}{|c|c|c|c|c|c|}
\hline & $\begin{array}{l}\text { Did not go into } \\
\text { remission } \\
(n=52)\end{array}$ & SD & $\begin{array}{l}\text { Diabetes } \\
\text { remission }(n=8)\end{array}$ & SD & $p$ value \\
\hline \multicolumn{6}{|l|}{ Outcomes } \\
\hline & & 23.7 & & 22. & \multirow{5}{*}{0.3830} \\
\hline Excess weight loss (\%) & 43.36 & 7 & 51.25 & 61 & \\
\hline Insulin cessation (\%) & 36.36 & & & & \\
\hline Metformin cessation (\%) & 11.11 & & & & \\
\hline \multirow[t]{2}{*}{ Sulphonylurea cessation (\%) } & 47.62 & & & & \\
\hline & & 29.4 & & 30. & \\
\hline Mean visits & 49.02 & 8 & 68.50 & 35 & 0.0883 \\
\hline Re-operation rate (\%) & 46.15 & & 75.00 & & 0.2542 \\
\hline
\end{tabular}

Excess weight loss (EWL) in the remission group was $51.25 \%$, and $43.36 \%$ in the non-remission group. Within the non-remission group, four patients had insulin cessation, four patients had metformin cessation and ten patients had sulphonylurea cessation.

\section{Conclusion}

In younger obese diabetic patients with better glycaemic control at baseline, LAGB can be an effective tool for diabetes remission in the long-term. Revisional surgery and gastric reflux symptoms are common LAGB complications that should be discussed with candidate patients.

\section{Acknowledgements}

We are grateful to our patients for their assistance. This work was supported by a competitive Diabetes Research Grant from Novo Nordisk, through Victorian State Government Operational Infrastructure Support and NHMRC Research Institute Infrastructure Support Scheme.

\section{Author Contributions}

JMW conceived the study. PEO, PRB, WAB, and SS provided surgical care and, with JMW, $C L$ and $C C$ collated the data. JMW and CC analyzed the data. JMW drafted the manuscript and all authors reviewed and edited it. JMW is the guarantor of this work and, as such, had full access to all the data in the study and takes responsibility for the integrity of the data and the accuracy of the data analysis. 